\title{
NEURODEVELOPMENT IN INFANTS WITH COMPLEX CONGENITAL HEART DEFECTS IN THE FIRST 6 MONTHS OF LIFE
}

\section{Jill C. Heathcock MPT, PhD, Janet Simsic MD, Tondi Harrison RN, PhD The Ohio State University \& Nationwide Children's Hospital}

Background and Aims

Infants with CCHD account for $2.5 / 1000$ births in the USA, require life-saving surgery, and often experience disabilities. While detection of CCHD happens in utero, any resulting motor and cognitive delays are rarely identified early. Because of the high impact of motor and cognitive disabilities to children, families, and society and encouraging results of early intervention, early identification of delay is paramount. The purpose of this study is to identify motor and cognitive delays, and brain injury in infants with CCHD and in healthy infants from birth to six months of age.

\section{Method}

$\mathrm{N}=30$ infants with $\mathrm{CCHD}$ and a comparison group of $\mathrm{N}=15$ healthy infants participated in this longitudinal study at birth, 3 months, and 6 months of age. Prechtl's GMs, the TIMP, and the Bayley-III were used to assess risk for CP and motor and cognitive delays. Non-sedation MRI of the brain was used to understand brain-behavior relationships.

\begin{tabular}{|l|l|l|}
\hline & CCHD (N=28) & TD (N=15) \\
\hline Gestational Age (weeks) & 38.86 & $* * *$ \\
\hline Birth Weight (kg) & 3.486 & 3.594 \\
\hline
\end{tabular}

\section{Results}

10/24 (41\%) infants with CCHD had abnormal GMs placing them at high risk for cerebral palsy and motor delay. Using independent $t$-tests, infants with CCHD demonstrated lower TIMP scores than infants with TD; $p=0.001$ indicating motor dysfunction. More than half of infants with CCHD had abnormal brain development measured with MRI. Some updated results:
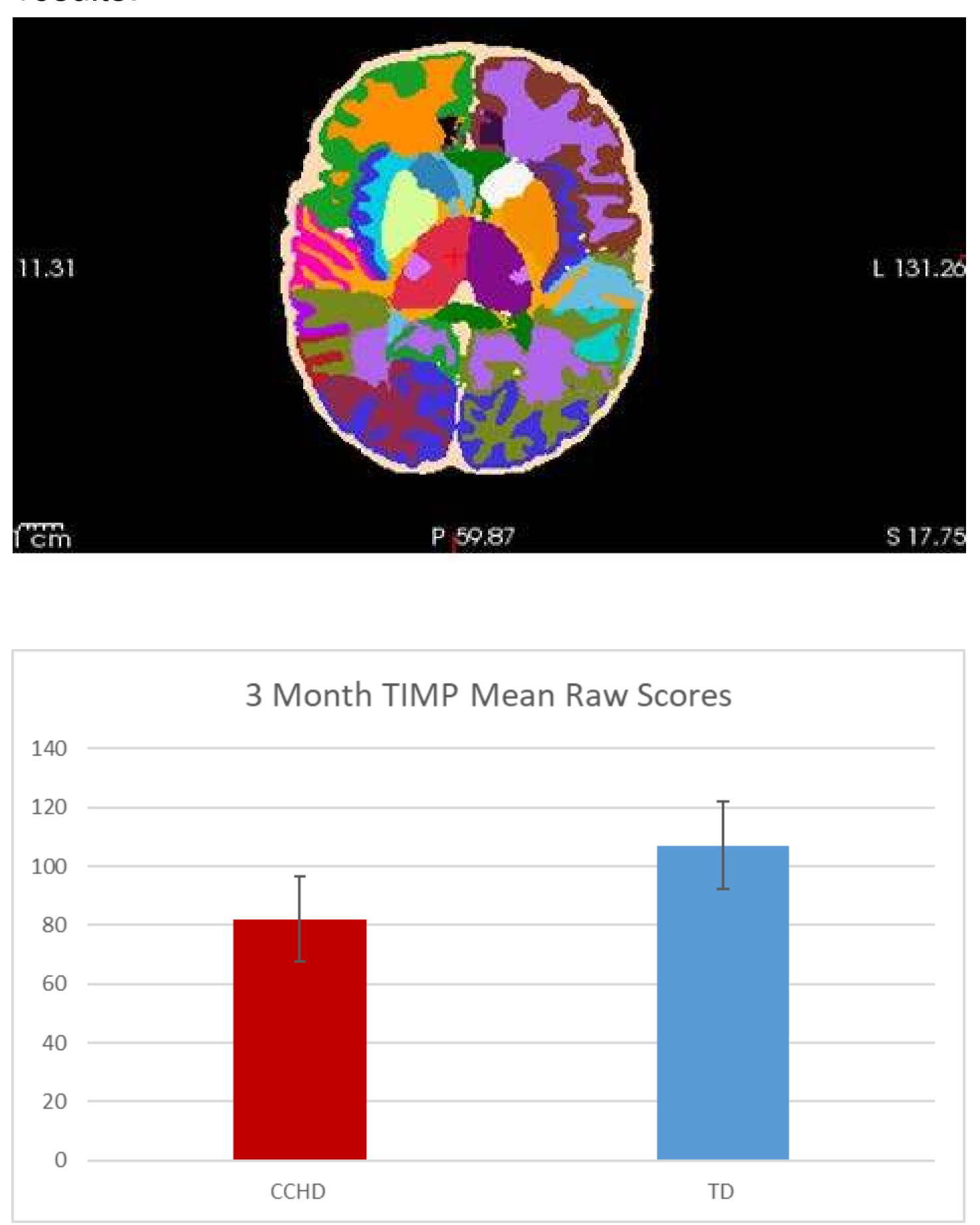

\section{Conclusion}

An earlier detection of motor delays and the relationship to brain structure and growth in infancy will allow clinicians to be proactive instead of reactive. Indicators of motor dysfunction and abnormal brain growth and development are prevalent in infants with CCHD.
Birth Abnormal GMs for CCHD ( $N=23$ )

$$
\text { 12/23 (52.17\%) Abnormal }
$$

$11 / 23$ (47.83\%) Normal
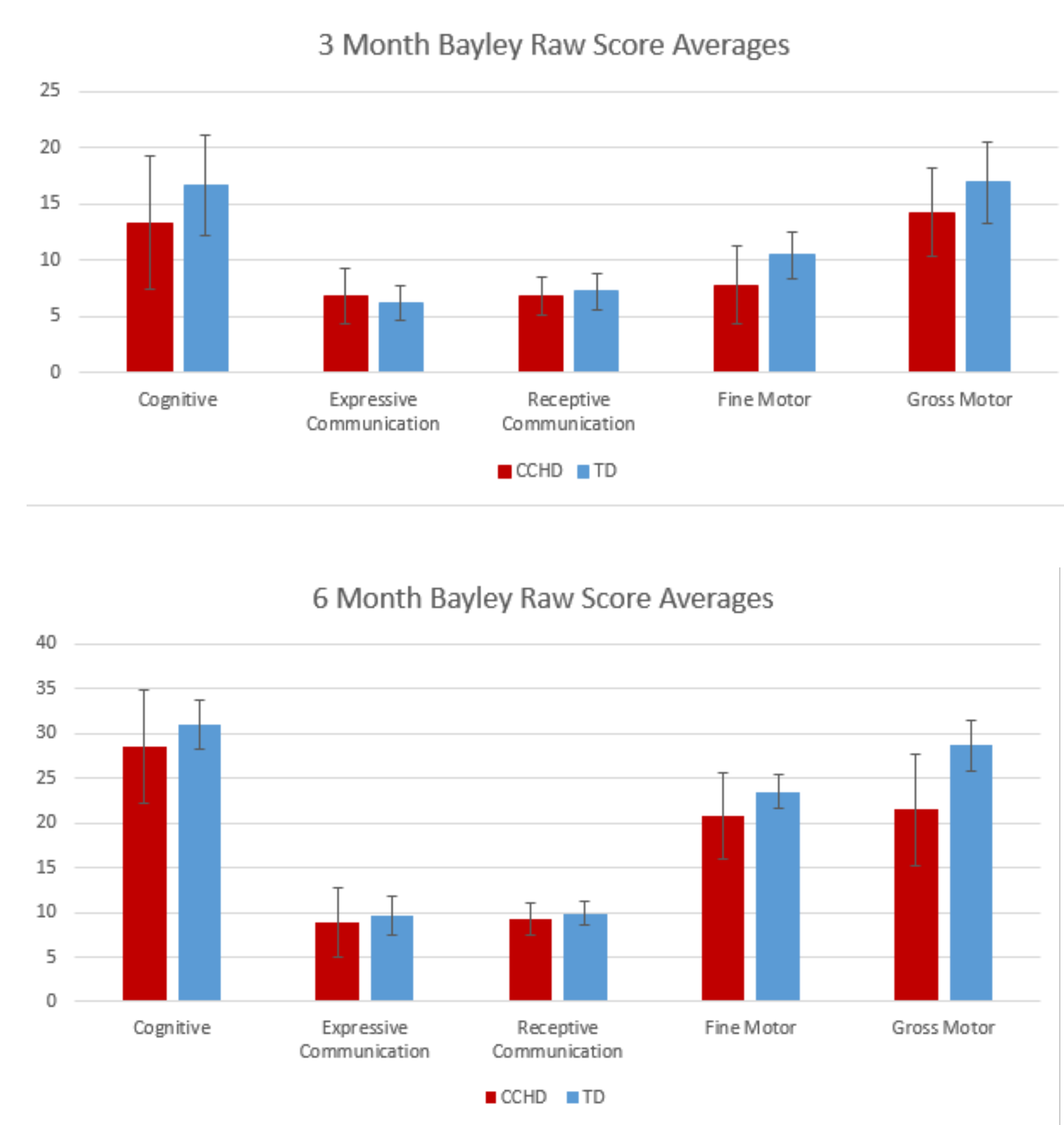

\begin{tabular}{|l|l|l|}
\hline $\begin{array}{l}6 \text { Month CCHD Scaled to Qualify for Services (Scaled } \\
\text { Score <8) }\end{array}$ & $\begin{array}{l}\text { Number of } \\
\text { Children }\end{array}$ & $\begin{array}{l}\text { Percentage } \\
(\mathrm{N}=25)\end{array}$ \\
\hline Cognitive & 5 & $20 \%$ \\
\hline Receptive Communication & 9 & $36 \%$ \\
\hline Expressive Communication & 5 & $20 \%$ \\
\hline Fine Motor & 5 & $20 \%$ \\
\hline Gross Motor & 14 & $56 \%$ \\
\hline
\end{tabular}

